\title{
ChemComm
}

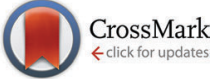

Cite this: Chem. Commun., 2016, 52,12893

Received 24th August 2016, Accepted 6th October 2016

DOI: $10.1039 / c 6 c c 06943 f$

www.rsc.org/chemcomm

\section{A drastic change in the superhydrophilic crystal porosities of metallosupramolecular structures via a slight change in $\mathrm{pH} \dagger$}

\author{
Sireenart Surinwong, Nobuto Yoshinari, Tatsuhiro Kojima and Takumi Konno*
}

\begin{abstract}
A unique $\mathrm{pH}$-controlled synthesis of two metallosupramolecular structures from $\mathrm{CO}_{2}^{\prime \prime \prime} \mathrm{Au}_{3}^{\prime}$ complex anions and $\mathrm{Zn}$ " cations is reported. A dense coordination polymer (porosity $\sim 13 \%$ ) was formed at a $\mathrm{pH}$ of 5.0 , whereas a porous ionic framework (porosity $\sim 61 \%$ ) that selectively adsorbs $\mathrm{CO}_{2}$ and $\mathrm{H}_{2} \mathrm{O}$ was created when the $\mathrm{pH}$ was adjusted to 5.5 .
\end{abstract}

The preparation of porous crystalline materials such as metalorganic frameworks (MOFs), coordination polymers (CPs), and porous ionic frameworks has received continuous attention not only because of these materials' fascinating structures but also because of their unique properties for gas storage and separation, chemical sensing, catalysis, etc. ${ }^{1-3}$ However, controlling the crystal porosities of this class of materials is frequently very difficult because of the effects of various synthesis parameters, including $\mathrm{pH}$, solvent, and concentration, on the interactions between the metal ions and ligands. ${ }^{4}$ Therefore, the systematic synthesis of porous crystalline materials with the desired porosity by controlling these external factors remains an important research topic.

$\mathrm{pH}$ is one of the external stimuli that most strongly influence the construction of porous crystalline materials. ${ }^{5}$ This influence stems from the effect of changes in $\mathrm{pH}$ on the protonation level, which drastically changes the coordination modes and conformations of ligands, the geometry of metal centres, and the intermolecular hydrogen bonding interactions. ${ }^{5,6}$ Previous reports on the $\mathrm{pH}$ effect on the production of MOFs revealed that a higher $\mathrm{pH}$ tends to give frameworks with greater dimensionality compared to those formed at a lower $\mathrm{pH}^{6}{ }^{6}$ However, a systematic approach to controlling crystal porosities by alteration of $\mathrm{pH}$ has thus far been much less explored.

Herein, we report a unique metallosupramolecular system that exhibits a drastic increase in crystal porosity with an increase

Department of Chemistry, Graduate School of Science, Osaka University, Toyonaka, Osaka560-0043, Japan.E-mail: konno@chem.sci.osaka-u.ac.jp

$\dagger$ Electronic supplementary information (ESI) available: Details of syntheses together with spectroscopic data, adsorption data, PXRD results, and singlecrystal X-ray diffraction data. CCDC 1500233 and 1500234. For ESI and crystallographic data in CIF or other electronic format see DOI: 10.1039/c6cc06943f in the $\mathrm{pH}$ of reaction solutions. This system involves a dense coordination polymer, $\left[\mathrm{Zn}\left(\mathrm{H}_{2} \mathrm{O}\right)_{4}\left\{\mathrm{Co}_{2} \mathrm{Au}_{3}(\mathrm{D}-\mathrm{Hpen}-\mathrm{N}, S)(\mathrm{D}-\mathrm{pen}-\mathrm{N}, S)_{5}\right\}\right]$ (1; porosity $\sim 13 \%$, D- $\mathrm{H}_{2}$ pen $=\mathrm{D}$-penicillamine), and a highly porous ionic compound, $\mathrm{Na}_{9}\left[\mathrm{Zn}(\mathrm{OAc})_{2}\left\{\mathrm{Co}_{2} \mathrm{Au}_{3}(\mathrm{D}-\text { pen- } N, S)_{6}\right\}_{2}\right]\left[\mathrm{Co}_{2} \mathrm{Au}_{3}(\mathrm{D}-\right.$ pen- $\left.N, S)_{6}\right]$ (2; porosity $\sim 61 \%$ ), both of which are independently produced from rod-shaped $\mathrm{Co}_{2}^{\text {III }} \mathrm{Au}_{3}^{\mathrm{I}}$ pentanuclear complex-anions $\left[\mathrm{Co}_{2} \mathrm{Au}_{3}(\mathrm{D}-\mathrm{pen}-\mathrm{N}, \mathrm{S})_{6}\right]^{3-7}$ and $\mathrm{Zn}^{2+}$ cations at slightly different solution pH levels (5.0 vs. 5.5) (Scheme 1). To the best of our knowledge, such a drastic increase in crystal porosity from a dense coordination polymer to a porous ionic compound has not been previously reported.

Solutions of $\left.\mathrm{Na}_{3}\left[\mathrm{Co}_{2} \mathrm{Au}_{3} \text { (D-pen- } N, S\right)_{6}\right]^{7}$ and $\mathrm{Zn}(\mathrm{OAc})_{2}$ in a sodium acetate buffer solution at $\mathrm{pH} 4.5(\mathrm{HOAc} / \mathrm{NaOAc}=1: 1)$ were mixed together, yielding insoluble purple crystals with a square block shape (1). $\dagger$ The crystallization of $\mathbf{1}$ was complete within a day, with a yield of $58 \%$. The diffuse reflection spectrum of 1 and the solid-state circular dichroism (CD) spectrum are similar to those of $\mathrm{Na}_{3}\left[\mathrm{Co}_{2} \mathrm{Au}_{3}(\mathrm{D} \text {-pen- } N, S)_{6}\right]$, indicating that the S-bridged pentanuclear structure in $\left[\mathrm{Co}_{2} \mathrm{Au}_{3}(\mathrm{D} \text {-pen- } N, S)_{6}\right]^{3-}$ is

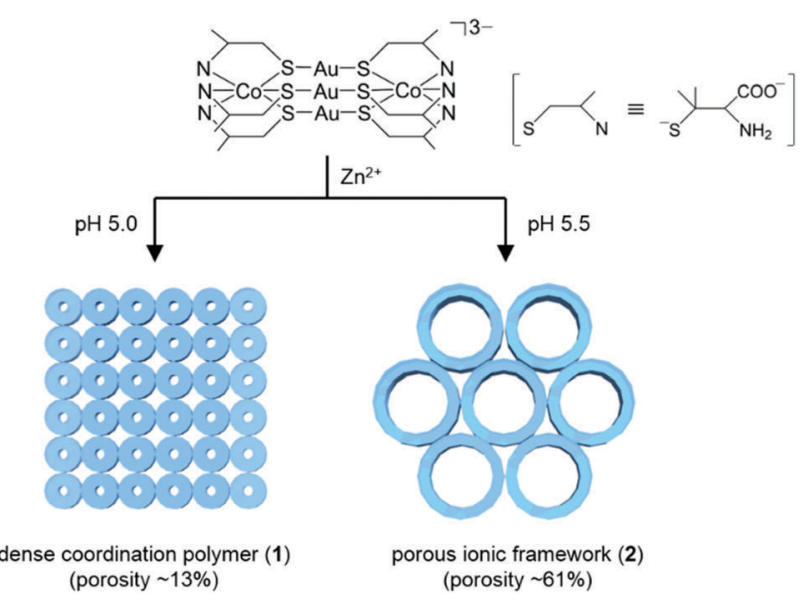

Scheme 1 Synthetic routes and schematics of two different metallosupramolecular structures $\left(\mathbf{1}\right.$ and 2 ) constructed from $\left[\mathrm{Co}_{2} \mathrm{Au}_{3}(\mathrm{D}-\text { pen-N,S })_{6}\right]^{3-}$ anions and $\mathrm{Zn}^{2+}$ cations at various $\mathrm{pH}$ values. 

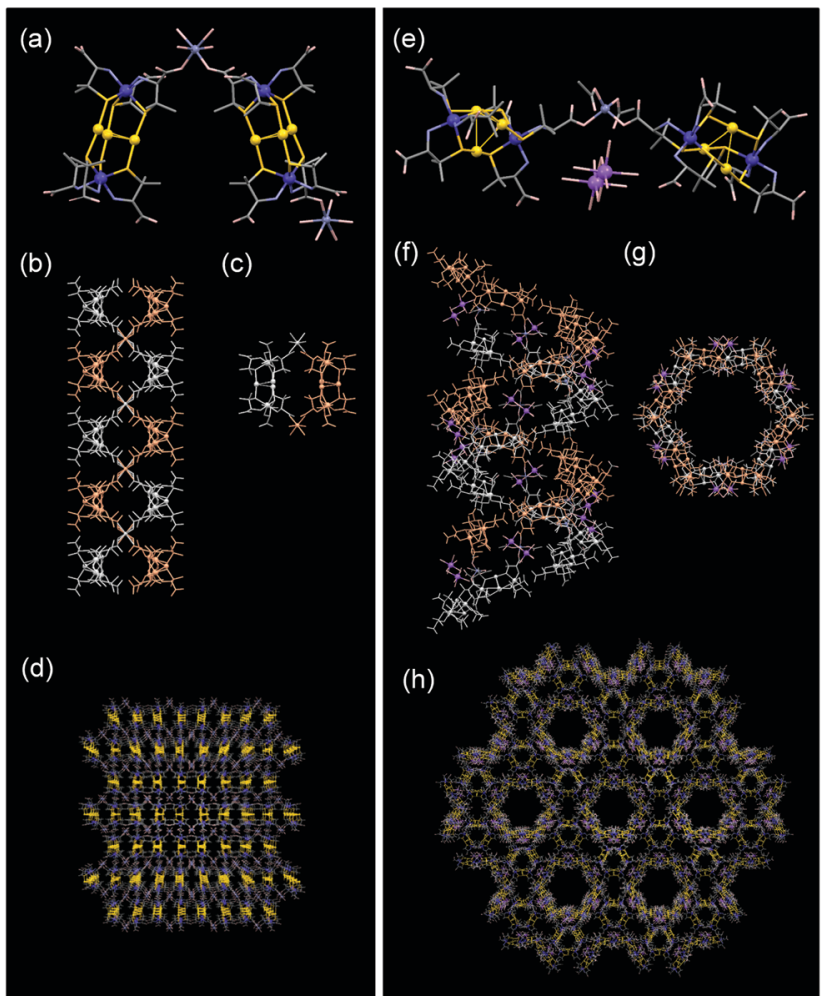

Fig. 1 Perspective views of (a) the expanded asymmetric unit, (b) side and (c) top views of the right-handed 2 -fold double helix structure (orange and white), and (d) a 3D dense structure with 1D coordination polymers in 1. Perspective views of (e) the expanded asymmetric unit, ( $f$ ) side and (g) top views of the right-handed 6 -fold double-helix structure (orange and white), and (h) a 1D channel structure in 2. Colour codes: Zn, dark grey; Na, red purple; Co, deep blue; Au, gold; S, yellow; O, pink; N, blue; C, grey. Dashed lines indicate hydrogen bonds.

retained in $\mathbf{1}$ (Fig. S1a and S2a). $\uparrow$ The IR spectrum of $\mathbf{1}$ shows an intense $\mathrm{C}=\mathrm{O}$ stretching band at $1609 \mathrm{~cm}^{-1}$ with a shoulder at $1717 \mathrm{~cm}^{-1}$. The former and the latter correspond to deprotonated $\mathrm{COO}^{-}$and protonated $\mathrm{COOH}$ groups, indicative of the partial protonation of carboxylate groups in 1 (Fig. S3). $\dagger^{8} \mathrm{X}$-ray fluorescence analysis confirmed the existence of $\mathrm{Zn}$ atoms, in addition to the Co and Au. Combining these results with the elemental analysis data, we predicted that 1 is a $1: 1$ adduct of $\mathrm{Zn}^{2+}$ and $\left[\mathrm{Co}_{2} \mathrm{Au}_{3}(\mathrm{D}-\mathrm{H} \text { en- } N, S)(\mathrm{D}-\text { pen- } N, S)_{5}\right]^{2-}$, in which one of the six D-pen carboxyl groups is protonated.

The structure of $\mathbf{1}$ was determined by single-crystal X-ray diffraction analysis. In addition to the water molecules of crystallization, 1 contains cis-configurational $\left[\mathrm{Zn}\left(\mathrm{H}_{2} \mathrm{O}\right)_{4}\right]^{2+}$ cations directly bound to $\left[\mathrm{Co}_{2} \mathrm{Au}_{3}(\mathrm{D}-\mathrm{Hpen}-N, S)(\mathrm{D}-\text { pen- } N, S)_{5}\right]^{2-}$ anions (Fig. 1a). In 1, $\left[\mathrm{Co}_{2} \mathrm{Au}_{3}(\mathrm{D}-\mathrm{H} \text { pen- } N, S)(\mathrm{D}-\text { pen- } N, S)_{5}\right]^{2-}$ anions are alternately connected by the $\left[\mathrm{Zn}\left(\mathrm{H}_{2} \mathrm{O}\right)_{4}\right]^{2+}$ cations through coordination bonds (av. $\mathrm{Zn}-\mathrm{OOC}=2.02 \AA$ ), forming a 2-fold helix along the crystallographic $a$ axis (Fig. 1b and c). Additionally, the two helices are intertwined and connected to each other through $\mathrm{OH}_{2} \cdots$ OOC hydrogen bonds (av. $\mathrm{O} \cdots \mathrm{O}=2.72 \AA$ ), forming a tight right-handed double-helix structure (Fig. S4 and S5). $\uparrow$ The double helices are connected to each other through $\mathrm{COOH} \cdots$ OOC intermolecular hydrogen-bonding interactions (av. O $\cdots \mathrm{O}=2.84 \AA$ ) to form a 2D sheet-like structure (Fig. S6). $\dagger$ Finally, the 2D sheets are stacked through $\mathrm{NH}_{2} \cdots$ OOC hydrogen bonds (av. $\mathrm{N} \cdots \mathrm{O}=2.98 \AA$ ), completing a 3D dense structure (Fig. 1d). The estimated solvent accessible volume of 1 was $\sim 13 \%$ on the basis of our calculations using the PLATON program. ${ }^{9}$

A similar treatment of $\mathrm{Na}_{3}\left[\mathrm{Co}_{2} \mathrm{Au}_{3}(\text { D-pen- } N, S)_{6}\right]$ and $\mathrm{Zn}(\mathrm{OAc})_{2}$ in a sodium acetate buffer solution at $\mathrm{pH} 5.0(\mathrm{HOAc} / \mathrm{NaOAc}=1: 2)$ also yielded only insoluble purple square block crystals of $\mathbf{1}$. New water-soluble purple hexagonal block crystals (2) were obtained when the $\mathrm{pH}$ of the buffer solution was increased to $5.5($ HOAc/NaOAc $=1: 6) . \dagger \$ \S$ The diffuse reflection and solidstate CD spectra of $\mathbf{2}$ are essentially the same as those of $\mathbf{1}$ (Fig. S1b and $\mathrm{S} 2 \mathrm{~b}) . \dagger$ However, the IR spectrum displays a $\mathrm{C}=\mathrm{O}$ stretching absorption only at $1611 \mathrm{~cm}^{-1}$ (Fig. S3), indicating that all carboxyl groups in 2 are deprotonated. $\dagger^{8}$ The X-ray fluorescence and elemental analysis results were in good agreement with a $1: 3$ adduct of $\mathrm{Zn}^{2+}$ and $\left[\mathrm{Co}_{2} \mathrm{Au}_{3}(\mathrm{D}-\text { pen- } N, S)_{6}\right]^{3-}$. In addition, ${ }^{23} \mathrm{Na}$ and ${ }^{1} \mathrm{H}$ NMR spectra revealed the presence of $\mathrm{Na}^{+}$and $\mathrm{OAc}^{-}$ions, respectively (Fig. S7 and $\mathrm{S} 8$ ). $\dagger$ Single-crystal X-ray analysis revealed that 2 consists of tetrahedral $\left\{\mathrm{Zn}(\mathrm{OAc})_{2}\right\}$ units, $\left[\mathrm{Co}_{2} \mathrm{Au}_{3}(\mathrm{D}-\text { pen- } N, S)_{6}\right]^{3-}$ anions, in addition to aqua $\mathrm{Na}^{+}$cations and water molecules of crystallization (Fig. 1e). In 2, $\left[\mathrm{Co}_{2} \mathrm{Au}_{3}\left(\mathrm{D}^{-}\right.\right.$ pen- $\left.N, S)_{6}\right]^{3-}$ anions are hydrogen bonded (av. $\left.\mathrm{N} \cdots \mathrm{O}=2.93 \AA\right)$ to each other to construct a six-fold helix with right handedness along the $c$ axis. The two helices are bridged by the $\left\{\mathrm{Zn}(\mathrm{OAc})_{2}\right\}$ moieties (av. $\mathrm{Zn}-\mathrm{O}_{\mathrm{OAc}}=1.96 \AA$ ) through coordination bonds (av. $\mathrm{Zn}-\mathrm{O}_{\text {pen }}=1.97 \AA$ ), resulting in a tubular double helix structure with a large $1 \mathrm{D}$ pore with a diameter of $c a .20 \AA$ (Fig. 1f and g). The double helices are further connected by other $\left[\mathrm{Co}_{2} \mathrm{Au}_{3}(\mathrm{D}-\text { pen- } N, S)_{6}\right]^{3-}$ anions via $\mathrm{NH}_{2} \cdots$ OOC hydrogen bonds (av. $\mathrm{N} \cdots \mathrm{O}=2.91 \AA$ ), completing a 3D framework that possesses 1D pore channels (Fig. 1h and Fig. S9). $\dagger$ The channels accommodate water molecules and $\mathrm{Na}^{+}$ions that are severely disordered. The estimated solvent accessible volume of 2 was $\sim 61 \%$. This $1 \mathrm{D}$ channel structure is supported by aqua $\mathrm{Na}^{+}$ cations, each of which forms $\mathrm{Na}-\mathrm{OH}_{2} \cdots$ OOC hydrogen bonds (av. $\mathrm{O} \cdots \mathrm{O}=2.83 \AA$ ) between two $\left[\mathrm{Co}_{2} \mathrm{Au}_{3}(\mathrm{D}-\text { pen- } N, S)_{6}\right]^{3-}$ anions and one $\left\{\mathrm{Zn}(\mathrm{OAc})_{2}\right\}$ unit in the double helix.

The spatial arrangement of $\left[\mathrm{Co}_{2} \mathrm{Au}_{3}(\mathrm{D}-\text { pen- } N, S)_{6}\right]^{3-}$ anions in 2 is reminiscent of that in the previously reported porous ionic crystal $\left[\mathrm{Co}\left(\mathrm{H}_{2} \mathrm{O}\right)_{4}\right]\left[\mathrm{Co}\left(\mathrm{H}_{2} \mathrm{O}\right)_{6}\right]_{2}\left[\mathrm{Co}_{2} \mathrm{Au}_{3}(\mathrm{D} \text {-pen- } N, S)_{6}\right]_{2}(3) .{ }^{10}$ The substitution of linking trans- $\left[\mathrm{Co}\left(\mathrm{H}_{2} \mathrm{O}\right)_{4}\right]^{2+}$ units and free $\left[\mathrm{Co}\left(\mathrm{H}_{2} \mathrm{O}\right)_{6}\right]^{2+}$ ions in 3 by $\left\{\mathrm{Zn}(\mathrm{OAc})_{2}\right\}$ units and $\left[\mathrm{Na}_{2}\left(\mathrm{H}_{2} \mathrm{O}\right)_{10}\right]^{2+}$ ions in 2 is the only substantial structural difference between 2 and 3 . However, the stabilities of $\mathbf{2}$ and $\mathbf{3}$ are quite different; a powder X-ray diffraction study demonstrated that 2 retains its crystallinity after being heated at $120{ }^{\circ} \mathrm{C}$ for $12 \mathrm{~h}$, whereas 3 collapses immediately even at room temperature (Fig. S10 and S11) $\dagger$ As previously mentioned, multiple hydrogen bonds exist between acetate groups from $\left\{\mathrm{Zn}(\mathrm{OAc})_{2}\right\}$ and aqua ligands in $\left[\mathrm{Na}_{2}\left(\mathrm{H}_{2} \mathrm{O}\right)_{10}\right]^{2+}$ units in 2 (Fig. S12) $†$ By contrast, no direct hydrogen-bonding interactions were observed between trans- $\left[\mathrm{Co}\left(\mathrm{H}_{2} \mathrm{O}\right)_{4}\right]^{2+}$ units and free $\left[\mathrm{Co}\left(\mathrm{H}_{2} \mathrm{O}\right)_{6}\right]^{2+}$ ions in 3 , which is most likely the reason for the substantial difference in stability between 2 and 3 .

The protonation and deprotonation of the carboxylate group at different $\mathrm{pH}$ values and in the presence/absence of an excess 
of $\mathrm{Na}^{+}$and $\mathrm{OAc}^{-}$ions in reaction solutions are potential causes of the drastic change in crystal porosity between 1 and 2 . In $\mathbf{1}$, the protonated D-pen carboxyl groups form strong intermolecular $\mathrm{COOH}$ - . OOC hydrogen bonds, which bring neighbouring helices much closer. Consequently, a dense structure with low porosity ( $\sim 13 \%$ ) was reasonably constructed. In this case, the presence of both the protonated and the deprotonated carboxylate groups in each complex anion in the $\mathrm{pH}$ range from 4.0 to 5.0 is reasonable. ${ }^{11}$ By contrast, a slight but higher $\mathrm{pH}$ value of 5.5 leads to a fully deprotonated form of $\mathrm{D}$-pen in $\mathbf{2}$. Unlike in $\mathbf{1}$, $\mathrm{Na}^{+}$and $\mathrm{OAc}^{-}$ions from the employed NaOAc buffer solution were incorporated into 2 . Both $\mathrm{Na}^{+}$and $\mathrm{OAc}^{-}$ions appear to be associated with the template-directed synthesis of 2, i.e. these ions form strong intermolecular hydrogen bonds to stabilize the $1 \mathrm{D}$ channel structure with substantially increased porosity. Presumably, the formation of $\mathbf{2}$ was accomplished with the aid of the stabilizing effect due to a large amount of $\mathrm{Na}^{+}$and $\mathrm{OAc}^{-}$ ions in a basic acetate buffer solution. However, we observed that 1 was also selectively produced using controlled experiments in the $\mathrm{pH}$ range from 4.0 to 5.0 when the reaction solutions contained the same amounts of $\mathrm{Na}^{+}$and $\mathrm{OAc}^{-}$ions as those of 2 (Fig. S13). $\dagger$ This is because a large part of $\mathrm{OAc}^{-}$ ions exist in a protonated form in this $\mathrm{pH}$ range to prevent the coordination to a $\mathrm{Zn}^{2+}$ centre. Thus, we concluded that $\mathrm{pH}$ is the dominant factor controlling the crystal porosities in the present metallosupramolecular system, changing the protonation/ deprotonation states of the carboxylate groups.

The gas adsorption properties of $\mathbf{1}$ and $\mathbf{2}$ were investigated. As shown in Fig. S14, the $\mathrm{CO}_{2}$ adsorption isotherm for $\mathbf{1}$ at $195 \mathrm{~K}$ displayed a type-I physical sorption isotherm, ${ }^{12}$ showing a gradual increase to $8.7 \mathrm{~cm}^{3} \mathrm{~g}^{-1}$ at $P / P_{0}=0.99$, with a low calculated BET surface area of $16 \mathrm{~m}^{2} \mathrm{~g}^{-1} \cdot \dagger$ A similar $\mathrm{CO}_{2}$ adsorption isotherm was observed for 2; however, the adsorption amounts increased to a saturation value of $29.3 \mathrm{~cm}^{3} \mathrm{~g}^{-1}$ at $P / P_{0}=0.99$ because of its higher porosity. The BET surface area calculated from the $\mathrm{CO}_{2}$ adsorption isotherm was also substantially greater: $66 \mathrm{~m}^{2} \mathrm{~g}^{-1}$. By contrast, the adsorption capacities of $\mathrm{N}_{2}$ gas for both compounds (Fig. S15 and S16) were very poor at $77 \mathrm{~K}\left(<5.0 \mathrm{~cm}^{3} \mathrm{~g}^{-1}\right) \dagger$ The adsorption properties toward small vapour molecules were also investigated. Although the degree of water molecule adsorption for $\mathbf{1}$ was quite small ( $5 \mathrm{~mol} \mathrm{~mol}^{-1}$ at $\left.P / P_{0}=0.90\right), 2$ exhibited an impressively high adsorption of $134 \mathrm{~mol} \mathrm{~mol}^{-1}\left(584 \mathrm{~cm}^{3} \mathrm{~g}^{-1}\right)$ at $P / P_{0}=0.90$ (Fig. 2). This adsorption value is comparable to those for MOFs with excellent water adsorption ability. $\uparrow^{13,14}$ Notably, the ionic compound 2 possesses a substantial advantage over the MOFs that are commonly insoluble in solution because it can be regenerated via a dissolution-crystallization process. In an adsorption-desorption cycle, a large hysteresis loop was observed for 2, which is typical for nanoporous materials with large pores. ${ }^{14}$ Remarkably, not only 1 but also 2 exhibited no adsorption ability toward EtOH and acetone molecules (Fig. S17 and S18), reflecting the superhydrophilic character of their porous structures surrounded by numerous hydrophilic groups. $\dagger^{15}$ Previously, similar superhydrophilic behaviour was observed for $\mathbf{3}$. However, the adsorption capacity of $\mathbf{2}$ is much

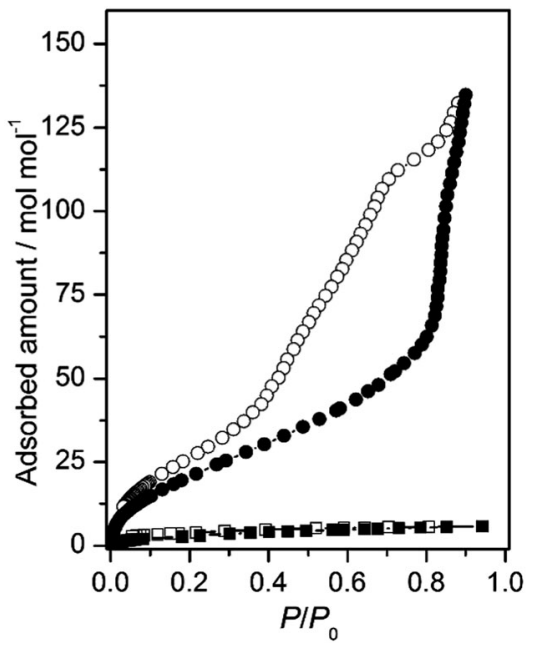

Fig. 2 Comparison of $\mathrm{H}_{2} \mathrm{O}$ adsorption (solid symbols) and desorption (open symbols) isotherms at $298 \mathrm{~K}$ for $\mathbf{1}$ (-口-) and 2 (-0 -).

greater than that of $3\left(33 \mathrm{~mol} \mathrm{~mol}{ }^{-1}\right.$ at $\left.P / P_{0}=0.90\right)$, which is ascribed to the very rigid porous framework in 2 .

In summary, we demonstrated that two metallosupramolecular compounds (1 and 2) of remarkably different porosities $(\sim 13 \%$ and $\sim 61 \%$, respectively) can be independently created from $\left[\mathrm{Co}_{2} \mathrm{Au}_{3}(\mathrm{D}-\text { pen- } N, S)_{6}\right]^{3-}$ anions and $\mathrm{Zn}^{2+}$ cations with only a slight change in solution $\mathrm{pH}(5.0$ vs. 5.5). Such a drastic change in crystal porosities by a slight change in $\mathrm{pH}$ has not been previously reported for crystalline coordination compounds. The formation of stable, superhydrophilic opening channels in 2, which are applicable for the selective inclusion of hydrophilic small molecules, is noteworthy. This study should serve as a guide for further development of the synthesis of reproducible, functional porous materials consisting of cationic and anionic species.

This work was supported by CREST, JST and JSPS KAKENHI Grant Number 15K21127 and 16K13609. The synchrotron radiation experiments were performed at the BL02B1 and BL02B2 beamlines of SPring-8 with the approval of the Japan Synchrotron Radiation Research Institute (JASRI) (Proposal No. 2015B1001, 2015B1237, 2016A1073) and at the 2D beamline in the Pohang Accelerator Laboratory supported by POSTECH.

\section{Notes and references}

$\ddagger$ Similar reactions in a sodium acetate buffer solution at $\mathrm{pH} 6.0$ and 6.5 also gave 2.

$\S$ When 1 was dissolved in a sodium acetate buffer solution of $\mathrm{pH} 5.5$, 2 was selectively crystallized after several days. The reverse conversion from 2 into 1 also occurred when a sodium acetate buffer solution of pH 5.0 was employed. $\dagger$

I Although the water adsorption amount of 2 is lower than the reported record for MOFs (PIZOF-2; $\left.850 \mathrm{~cm}^{3} \mathrm{~g}^{-1}\right),{ }^{13}$ this is the highest value for a porous ionic framework.

1 (a) S. Kitagawa, R. Kitaura and S. Noro, Angew. Chem., Int. Ed., 2004, 43, 2334; (b) J. R. Li, R. J. Kuppler and H. C. Zhou, Chem. Soc. Rev., 2009, 38, 1477; (c) R. Eguchi, S. Uchida and N. Mizuno, Angew. Chem., Int. Ed., 2012, 51, 1635; (d) R. Eguchi, S. Uchida and N. Mizuno, J. Phys. Chem. C, 2012, 116, 16105; (e) S. Uchida, R. Kawahara, Y. Ogasawara and N. Mizuno, Dalton Trans., 2013, 42, 16209; $(f)$ H. Furukawa, K. E. Cordova, M. O'Keeffe and O. M. Yaghi, Science, 2013, 341, 974; (g) Y. Mito-oka, Y. Sawada, 
T. Masumori, S. Horike, H. Kitagawa and S. Kitagawa, Chem. Lett., 2015, 44, 1694.

2 (a) L. E. Kreno, K. Leong, O. K. Farha, M. Allendorf, R. P. Van Duyne and J. T. Hupp, Chem. Rev., 2012, 112, 1105; (b) Y.-W. Li, J.-R. Li, L.-F. Wang, B.-Y. Zhou, Q. Chen and X.-H. Bu, J. Mater. Chem. A, 2013, 1, 495; (c) Z. Dou, J. Yu, Y. Cui, Y. Yang, Z. Wang, D. Yang and G. Qian, J. Am. Chem. Soc., 2014, 136, 5527.

3 (a) N. Guillou, Q. Gao, P. M. Forster, J. S. Chang, M. Noguès, S. E. Park, G. Férey and A. K. Cheetham, Angew. Chem., Int. Ed., 2001, 40, 2831; (b) A. Proust, R. Thouvenot and P. Gouzerh, Chem. Commun., 2008, 1837; (c) J. Lee, O. K. Farha, J. Roberts, K. A. Scheidt, S. T. Nguyen and J. T. Hupp, Chem. Soc. Rev., 2009, 38, 1450; (d) Z.-J. Liu, S. Yao, Z.-M. Zhang and E.-B. Wang, RSC Adv., 2013, 3, 20829; (e) R. Kawahara, K. Niinomi, J. N. Kondo, M. Hibino, N. Mizuno and S. Uchida, Dalton Trans., 2016, 45, 2805.

4 (a) N. Stock and S. Biswas, Chem. Rev., 2012, 112, 933; (b) D. Kim, X. Song, J. H. Yoon and M. S. Lah, Cryst. Growth Des., 2012, 12, 4186; (c) T. Liu, D. Luo, D. Xu, H. Zeng and Z. Lin, Inorg. Chem. Commun., 2013, 29, 110; (d) P.-Z. Li, X.-J. Wang, Y. Li, Q. Zhang, R. H. D. Tan, W. Q. Lim, R. Ganguly and Y. Zhao, Microporous Mesoporous Mater., 2013, 176, 194; (e) Y.-X. Sun and W.-Y. Sun, Chin. Chem. Lett., 2014, $25,823$.

5 (a) R.-Q. Zhong, R.-Q. Zou, M. Du, T. Yamada, G. Maruta, S. Takeda and Q. Xu, Dalton Trans., 2008, 2346; (b) H. Wang, Y.-Y. Wang, G.-P. Yang, C.-J. Wang, G.-L. Wen, Q.-Z. Shi and S. R. Batten, CrystEngComm, 2008, 10, 1583; (c) B. Zheng, J. Bai and Z. Zhang, CrystEngComm, 2010, 12, 49; (d) J.-X. Yang, X. Zhang, J.-K. Cheng, J. Zhang and Y.-G. Yao, Cryst. Growth Des., 2012, 12, 333; (e) H.-N. Wang, G.-S. Yang, X.-L. Wang and Z.-M. Su, Dalton Trans., 2013, 42, 6294; $(f)$ K. P. Rao,
M. Higuchi, J. Duan and S. Kitagawa, Cryst. Growth Des., 2013, 13, 981; (g) C. Patzschke, C. M. Forsyth, S. R. Batten and A. L. Chaffee, CrystEngComm, 2014, 16, 6296.

6 (a) S.-T. Wu, L.-S. Long, R.-B. Huang and L.-S. Zheng, Cryst. Growth Des., 2007, 7, 1746; (b) R.-G. Lin, L.-S. Long, R.-B. Huang and L.-S. Zheng, Inorg. Chem. Commun., 2007, 10, 1257; (c) Q. Chu, G.-X. Liu, T. Okamura, Y.-Q. Huang, W.-Y. Sun and N. Ueyama, Polyhedron, 2008, 27, 812; (d) M. Kouno, Y. Miyashita, N. Yoshinari and T. Konno, Chem. Lett., 2015, 44, 1512.

7 T. Konno, A. Toyota and A. Igashira-Kamiyama, J. Chin. Chem. Soc., 2009, 56, 26.

8 K. Nakamoto, Infrared and Raman Spectra of Inorganic and Coordination Compounds, Wiley, Chichester, 5th edn, 1997.

9 A. L. Spek, J. Appl. Crystallogr., 2003, 36, 7.

10 S. Surinwong, N. Yoshinari, B. Yotnoi and T. Konno, Chem. - Asian J., 2016, 11, 486.

11 N. Yoshinari, K. Tatsumi, A. Igashira-Kamiyama and T. Konno, Chem. - Eur. J., 2010, 16, 14252.

12 K. S. W. Sing, D. H. Everett, R. A. W. Haul, L. Moscou, R. A. Pierotti, J. Rouquerol and T. Siemieniewska, Pure Appl. Chem., 1985, 57, 603.

13 H. Furukawa, F. Gándara, Y.-B. Zhang, J. Jiang, W. L. Queen, M. R. Hudson and O. M. Yaghi, J. Am. Chem. Soc., 2014, 136, 4369.

14 (a) J. Canivet, A. Fateeva, Y. Guo, B. Coasne and D. Farrusseng, Chem. Soc. Rev., 2014, 43, 5594; (b) N. C. Burtch, H. Jasuja and K. S. Walton, Chem. Rev., 2014, 114, 10575.

15 (a) A. Nalaparaju, X. S. Zhao and J. W. Jiang, J. Phys. Chem. C, 2010, 114, 11542; (b) A. Kobayashi, A. Sugiyama, T. Ohba, Y. Suzuki, H.-C. Chang and M. Kato, Chem. Lett., 2014, 43, 1070; (c) J. J. Gutiérrez-Sevillano, S. Calero and R. Krishna, J. Phys. Chem. C, 2015, 119, 3658. 